\title{
Damage evaluation of drilled carbon/epoxy laminates based on area assessment methods
}

Luís Miguel P. Durão, João Manuel R.S. Tavares, Victor Hugo C. de Albuquerque, Daniel J.S. Gonçalves

\begin{abstract}
The characteristics of carbon fibre reinforced laminates had widened their use, from aerospace to domes- tic appliances. A common characteristic is the need of drilling for assembly purposes. It is known that a drilling process that reduces the drill thrust force can decrease the risk of delamination. In this work, delamination assessment methods based on radiographic data are compared and correlated with mechanical test results (bearing test).
\end{abstract}

Keywords: Carbon fibre, Machining, Radiography, Damage assessment, Testing

\section{Introduction}

The extensive use of composites, from aircrafts to sporting goods, increases the demand for optimized solutions considering production at reasonable costs and high level of quality. Advanta- ges in their use are related with their lightweight characteristics combined with good mechanical properties. The importance and usage of composite materials have been growing in latest years, which can be confirmed by their intensive use in the new Airbus A380 or Boeing 787 airplanes. In the latter, $50 \%$ of the weight of its primary aircraft structure will be made of composite materials [1]. One can now find composite materials not only in the aeronau-tical field, but also in other industries like automotive, railway, marine or of sport goods.

As parts in composite materials are to be usually assembled in complex structures, joining of these parts is always needed. Drilling is the most common machining operation in industry. Drilling is a complex process, characterized by the existence of extrusion and cut mechanisms. The former is performed by the drill chisel edge that has null or negligible linear speed and the latter by the existence of rotating cutting lips at a certain speed. The most common drill is the conventional conical point drill. The cutting process is unique and can be divided into two distinct regions: chisel edge and cutting lips. In a common drill, there is a small region around the centre of the chisel edge, called the indentation zone, where the tool does not cut the material, but extrudes it instead. At the region outside the indentation zone, called the secondary cutting edge area, the rake angle is highly negative. As fibre reinforced plastics are more brittle than metals, it is unlikely that extrusion really takes place and orthogonal cutting could be assumed for the entire chisel edge. However, model predictions based on this assumption do not agree with the experimental data. Along the cutting lips, cutting action of a drill is a three-dimensional oblique cutting process. The cutting speed, rake angles and other geometrical parameters vary along the cutting lips with the radial distance from the centre. The cutting action is more efficient at the outer regions of the cutting lips than near the drill's centre [2]. When

considering the drilling of a composite part, good results are mainly fibre related and less dependent on the matrix material [3]. Due to the high abrasive nature of carbon fibers, combined with the laminar nature of parts, several damages are due to occur dur- ing drilling operations, like push-down delamination, fiber pull-out or thermal damages [4]. The most frequent and noticeable evidence of these damages is the existence of an edge around the machined hole, namely at the exit side of the drill, as a consequence of the drilling process. In this region, it is possible to observe, by visual or enhanced inspection, the separation of adjacent plies of the laminate. This damage is known as delamination.

Delamination is considered as one of the most critical damages that can occur as it can contribute to a decrease in the mechanical 
strength of the part. These damages can affect not only the load carrying capacity of laminated parts but also strength and stiffness, thus reliability [5]. Rapid tool wear, due to material abrasiveness and matrix softening, due to heat buildup, can also be an important factor in damage occurrence [6]. Another consequence is the need of frequent tool changes that affects the production cycle and raises the final cost. Therefore, the reduction of this damage is of capital importance to the industry of composites.

The importance of tool geometry in delamination reduction is evidenced by several published works on the subject. For example, Piquet et al. [7] suggested the use of a greater number of cutting edges, from three to six, in order to increase the contact length between tool and part, a point angle of $118^{\circ}$ and a small rake angle. Chisel edge should be as reduced as possible. Park et al. [8] applied the helical-feed method to avoid fuzzing and delamination. The use of helical feed allows for an efficient completion of the drilling operation avoiding depth limitation. Stone and Krishnamurthy [9] studied the implementation of a neural network thrust force controller. The control scheme can minimize delamination by varying feed rate in order to control thrust force. Persson et al. [5] presented an orbital drilling method, in which the hole is machined simultaneously axially and radially. This method eliminates the stationary tool centre, thus reducing the axial force, reduces the risk of tool clogging and allows for the use of one tool diameter to machine several hole diameters. Davim and Reis [10] studied the effect of cutting parameters on specific cutting pressure, delamination and cutting power in carbon fibre reinforced plastics. These authors concluded that the feed rate has greater influence on thrust force, so damage increases with feed. Tsao and Hocheng [11] analyzed the effect of a backup plate on delamination, in order to understand and explain the advantage of its use in composite laminate drilling. Experimental findings revealed that the use of a backup plate causes an increase in the critical thrust force, allow- ing for higher feed rates. The possibility of actual use of this plate can be an issue in the construction and maintenance of structures. In another work [12], Hocheng and Tsao conducted several practi- cal experiences to prove the benefit of using a special drill when compared to commercially available tools, like twist drill. The effect of their use on delamination was evaluated. Delamination extent was determined with the help of ultrasonic C-Scan. At the end, it was possible to conclude that thrust force varies with drill geometry and with feed rate. That enables for the use of higher feed rates if adequate drill geometry is selected. More recently, Tsao and Hocheng [13] have presented the advantages of a core drill. The influence of spindle speed was relatively insignificant. Fernandes and Cook [14] investigated the thrust force during drilling with "one shot" drill bit. Their objective was to extend tool life and improve hole quality. For that, a mathematical model leading to the calculation of feed in order to keep the thrust force under a critical threshold was developed. Finally, Tsao $[15,16]$ evaluated the importance of pilot hole on delamination reduction when using core drills and saw drills. Pilot hole eliminates the chisel edge ef- fect, reducing delamination hazard. The ratio of pre-drilled hole to drill diameter must be controlled in order to drill with higher feed rate without delamination. In his experimental work, Tsao has found an optimal ratio of 0.85 for the use of the largest feed rate $-0.012 \mathrm{~mm} / \mathrm{rev}$. Dharan and Won [17] conducted a series of machining experiments in order to propose an intelligent machin- ing system that avoids delamination by peel-up at entrance and by push-down at exit. Such a system should be able to limit feeds when the tool contacts the plate and before drill breakthrough, avoiding delamination onset.

As carbon fibre/epoxy laminates are opaque some of these damages are not visible in a visual inspection, so it is needed

to establish non-destructive testing (NDT) in order to determine the

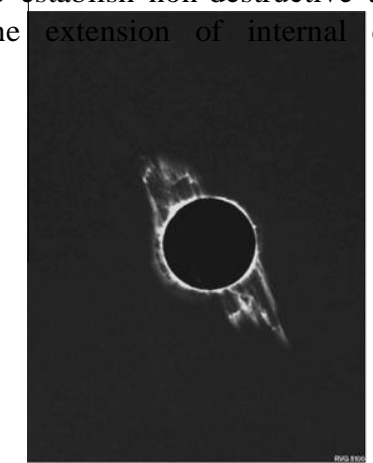

(a)

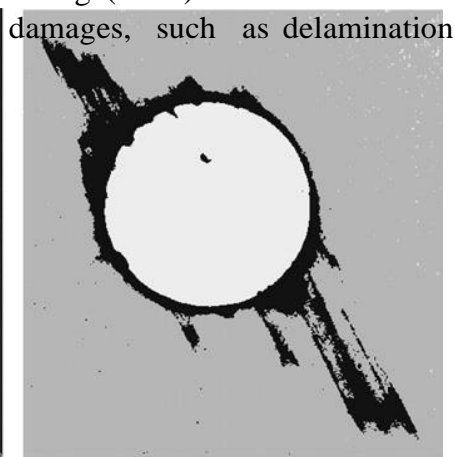

(b)

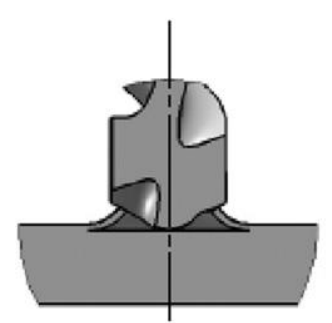

(a)

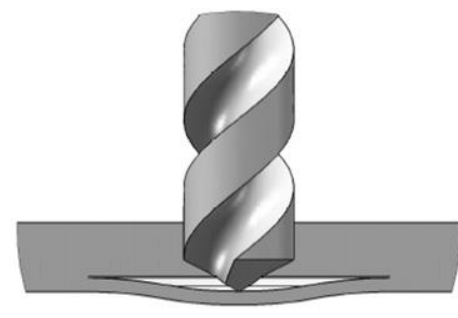

(b) 
Fig. 2. Delamination mechanisms: (a) peel-up delamination at entrance; (b) push- down delamination at exit.

Fig. 1. (a) Enhanced radiography of a drilled composite laminate; (b) damage region identified using techniques of image processing and analysis.

Digital images are also used to assess this type of damage after drilling [18].

Enhanced radiography, a non-destructive inspection method, can help on the identification and measurement of the delaminated area or diameter around the hole (Fig. 1). Delamination assessment can be attained with the help of existing models that combine the delaminated diameter or damaged area with hole nominal diameter or area $[18,19]$ or even by the rounding of the cutting edge [20].

In this work, a batch of carbon/epoxy plates was drilled with different drills and the resultant delamination extensions were measured from digital enhanced radiographies that were evaluated using computational techniques of image processing and analysis $[21,22]$. Afterwards, the measurement results were used to correlate two traditional damage models $[18,19]$ and compare them to a new model that takes into account the shape of the damage areas agreed by a circularity index. Finally, the results of the three damage models were correlated with the bearing test, ASTM D-5961M-10[23].

Experimental findings confirmed that the damage models used are useful to evaluate the drilling process of composite laminates in complex structures and suitable to assist on delamination reduction objectives.

\section{Delamination in polymeric matrix composites}

\subsection{Delamination mechanism}

When delamination is concerned, it is necessary to consider two types of damage that are different in causes and effects: peel-up delamination and push-down delamination, Fig. 2.

Peel-up delamination, Fig. 2a, is a consequence of the cutting force pushing the abraded and cut materials to the flute surface. 


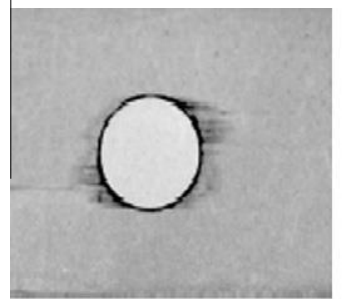

(a)



(b)

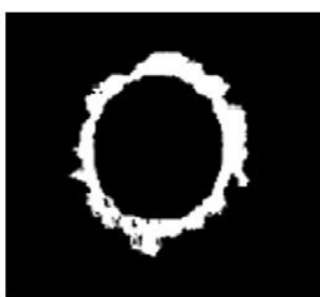

(c)

Fig. 3. Damage evaluation: (a) radiography; (b) C-Scan [33]; and (c) computerized tomography [33].

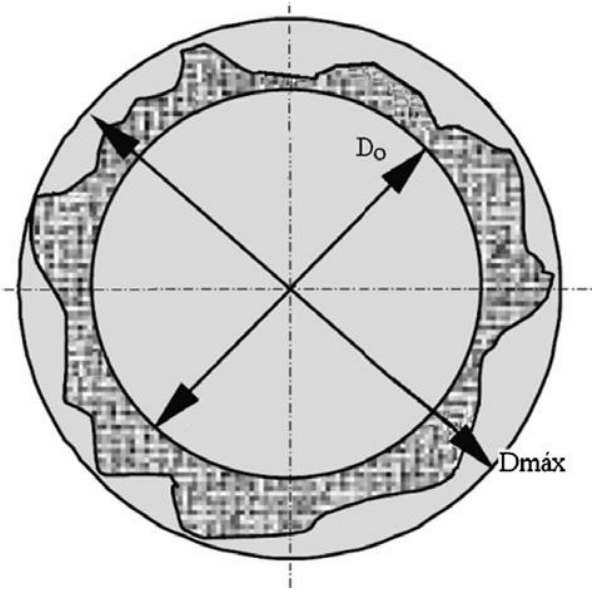

Fig. 4. Measurement of the maximum delaminated and hole diameters.

The material spirals up the drill flute before it is completely machined. A peeling force pointing upwards is introduced that tend to separate the upper lamina of the uncut portion held by the downward acting thrust force. Normally, a reduction in feed rate can reduce this delamination type.

Push-down delamination, Fig. $2 b$, is a damage that occurs in interlaminar regions, so it depends not only on fibre nature, but also on resin type and respective properties. This damage is a consequence of the compressive thrust force that the drill chisel edge always exerts on the uncut laminate plies. There is a certain point at which the loading exceeds the interlaminar bond strength and delamination occurs. The reduction of this delamination type is the main focus of this work.

Analysis of delamination mechanisms during drilling using Linear Elastic Fracture Mechanics (LEFMs) based approach have been developed and different models presented. The one most referred to is the Hocheng and Dharan [24] delamination model. In this model, the critical thrust force for the onset of delamination, $F_{c r i t}$, is related with properties of the unidirectional laminate, such as the elastic modulus, $E 1$, the Poisson ratio, $m 12$, the interlaminar fracture toughness in mode I, GIc, and the uncut plate thickness $(h)$ :

$$
F_{c t \boldsymbol{t}}=\pi\left[\frac{8 G_{1 k} E_{1} h^{3}}{3\left(1-v_{12}^{2}\right)}\right]^{1 / 2}
$$

through NDT. Some examples are the use of a tool maker's microscope [10,26-28], ultrasound techniques [29], acoustic emission [30], enhanced radiography [31,32] - Fig. 3a, C-Scan [33] Fig. 3b or Computerized Tomography (CT) [34,35] - Fig. 3c. In all these methods, the main goal is to obtain images representing the hole surrounding areas that can be further analyzed and mea- sured, mainly for diameters and areas.

Then, it is possible to carry out the quantification of the damaged region in order to calculate a factor that numerically expresses the damaged region extension and shape, Fig. 3. Chen [19] presented a comparing factor that enables the evaluation and analysis of delamination extent in laminated composites. That ratio was called the delamination factor, $F d$, and it was defined as the quotient between the maximum delaminated diameter, $D_{\max }$, see Fig. 4, and the hole nominal diameter, $D$ :

$$
F_{d}=D_{\max } / D
$$

In the experimental work presented in [19], the author examined the effects of tool geometry and cutting parameters as well as tool wear on the delamination factor. Two types of drills were used: a carbide drill and a HSS drill with $5 \mathrm{~mm}$ diameter. Damage zone was evaluated by using radiographic non-destructive inspection. Results showed a near-linear relationship between the delamination factor and average thrust forces for both drill materials. The author also concluded that thrust force increased when drill point angle increases and that helix angle did not have a significant effect on this force. Tool flank wear causes an increase of the delamination factor, as thrust force increases with tool wear.

Although the feed rate has a strong influence on the thrust force, the cutting speed has not shown a significant effect on that force. Finally, the author has noticed the absence of built up edge during carbon/epoxy machining.

Mehta et al. [36] have suggested a different ratio with the same purpose, named Damage Ratio, DRAT, defined as the ratio of Hole Peripheral Damage Area, DMAR, to Nominal Drilled Hole Area, $A A V G$, i.e.:

$$
D_{R E}=D_{M R R} / A_{\text {QVG }}
$$

This hole damage evaluation method is based on the existence of damage images from C-Scan and pixel counting of the digitized damage area, as described in [36], or from digitized radiographs [37].

One limitation of Chen's criterion is related with situations 





A comprehensive summary of the steps towards free-delamination holes can be found in [25].

\subsection{Delamination assessment}

After laminate holes are drilled, it is important to establish criteria that can easily compare the delamination extension caused by different machining processes. Damage extension can be evaluated are more appropriated for the damage quantification. Based on this, Davim et al. [18] presented a novel approach known as the Adjusted Delamination Factor, $F d a$,
where
$F_{d a}=\alpha \frac{D_{\max }}{D}+\beta \frac{A_{\max }}{A}$,
(4) Amax is

the area

corresponding to the maximum delaminateddiameter, $D \max$, and $A$ is the nominal hole area. In this new criterion, 

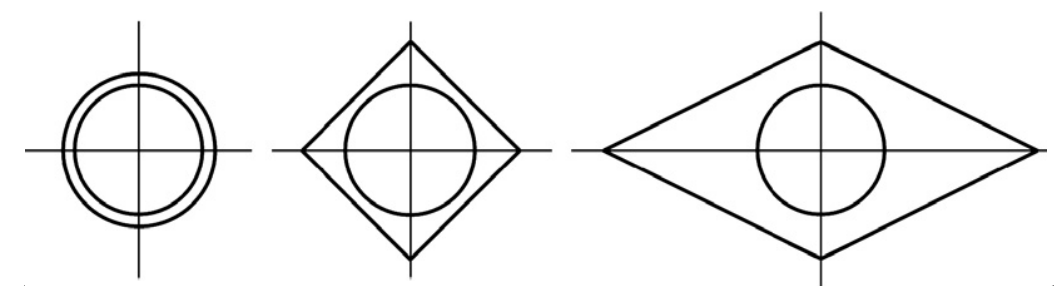

rig. s. Circularily exampies: (a) circie, $J=1$; (D) square, $J=$ v. 1 ; ; anu (c) diamond shape, $f=0.63$.

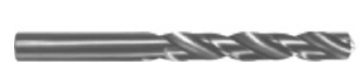

(a)

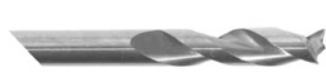

(b)

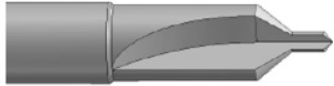

(c)

Fig. 6. Drills: (a) twist; (b) Brad; (e) bidiametral [21].

the first term is the conventional delamination factor and a second term is added, taking into account the damaged area contribution, and the parameters $a$ and $b$ are used as weights, being their sum always equal to 1 (one).

In this work, we suggest that the shape of the damaged area should be taken into account. That shape can be related with circularity, defined as a function of the perimeter, $P$, and the area, $A$, of the damaged area around the machined hole as $f$ :

$$
f=4 \pi \frac{A}{P^{2}}
$$

The value of circularity equals 1 (one) for a perfect circle and much lower for distended shapes, as is demonstrated by Fig. 5, for three different shapes: a circle, a square and a diamond-shaped quadrangle.

The final goal in this work was to find a correlation between mechanical resistance and damage extension, combining a delamination criterion with the circularity value.

\section{Materials and methods}

\subsection{Composite plates production and drilling}

For the experimental work, a batch of unidirectional carbon/ epoxy plates using prepreg CC160 ET 443 with 24 layers and a final thickness of $4 \mathrm{~mm}$ were produced. The plates were then cured for $1 \mathrm{~h}$ under $300 \mathrm{kPa}$ pressure and $130^{\circ} \mathrm{C}$, followed by cooling. Then, the plates were cut into test coupons of $135 \times 36 \mathrm{~mm}^{2}$ for the drilling experiments according to the bearing test specifications.
The experimental work was divided in drilling of the laminate plates, delamination measurement by enhanced radiography and computational algorithms of computational vision and mechanical tests. Composite coupons were tested according to ASTM D5961 bearing test. The results of delamination damage assessment and bearing stress were compared and correlated in order to enable the conclusions of this work.

The drilling operation was carried out in a $3.7 \mathrm{~kW}$ DENFORD Triac Centre CNC machine. As it has been previously identified the main importance of feed rate when compared with spindle speed in thrust forces development [31], the cutting speed was kept constant and equal to $2800 \mathrm{rpm}$ and the feed rate had three levels: low feed rate of $0.03 \mathrm{~mm} / \mathrm{rev}$, intermediate feed rate equal to $0.10 \mathrm{~mm} / \mathrm{rev}$ and high feed rate of $0.20 \mathrm{~mm} / \mathrm{rev}$. These cutting parameters were selected according to previous published works $[21,22,31,37]$ as well as tool manufacturer's recommendation. A tool diameter of $6 \mathrm{~mm}$ was used combined with three drill geometries: twist, Brad and bidiametral, see Fig. 6. Details on the drills can be found in [21].

\subsection{Delamination assessment}

After the drilling process, the delaminated region around the drilled hole was evaluated using enhanced digital radiography. In order to generate a contrast, the plates were first immersed in diiodomethane for approximately $15-20 \mathrm{~min}$. Then the radio-graphic images were acquired using a $60 \mathrm{kV}, 300 \mathrm{kHz}$ Kodak 2100 X-ray system associated with a Kodak RVG 5100 digital acquisition system. Exposition time was set to $0.125 \mathrm{~s}$.



(a)

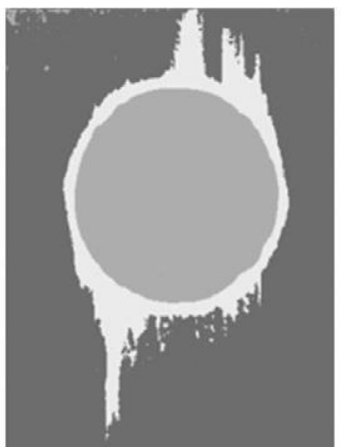

(b)

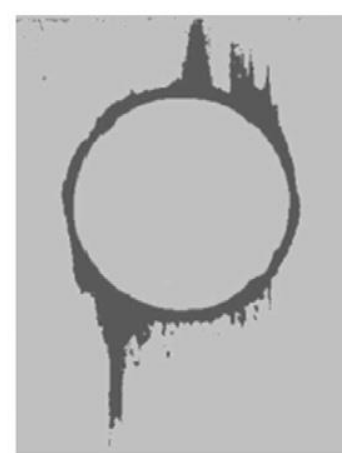

(c)

Fig. 7. Example of processing a radiographic image: (a) original image, (b) image segmented by using a neuronal network and (c) identification of the delamination region [31]. 


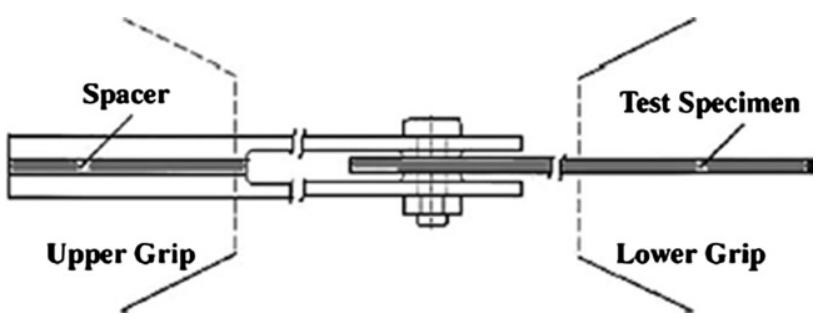

Fig. 8. Bearing test setup [42].

Each radiographic image was computationally processed in order to identify and characterize the regions of interest: hole region, delaminated and non-delaminated regions. The hole region corresponds to the central area, the delaminated region consists on a dark border around the machined hole, and the non-delaminated regions are lighter areas located outside the damaged region, Fig. $7 \mathrm{a}$ and c [31]. Fig. $7 \mathrm{~b}$ is a negative image, hence lighter area is the delaminated region around the hole.

The final objective of the image processing and analysis performed was to measure the damaged diameters and areas in each radiographic image. This was achieved by using in the image seg-

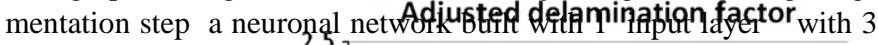
neurons, 1 hidden layer with 7 neurons [38], 1 output layer with 3 neurons, and the logistic function [39] as the neurons activation

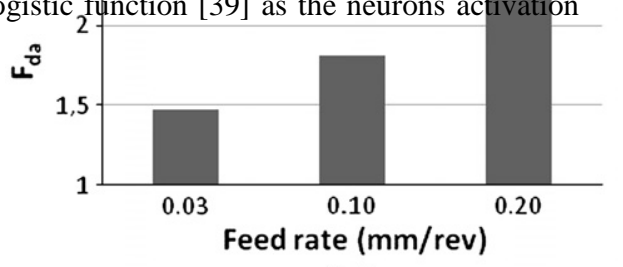

(a)

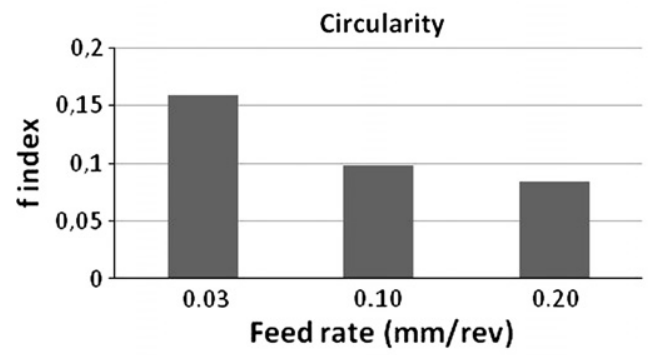

(c)

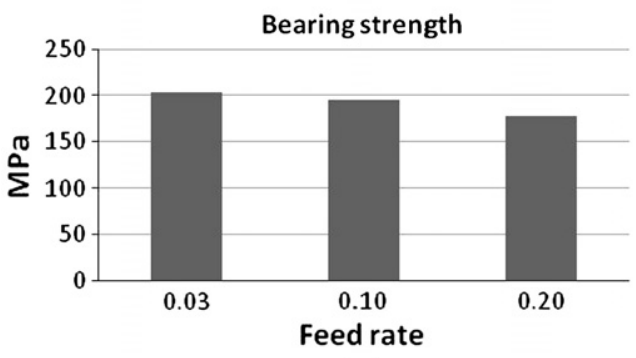

(e) function, which was trained using the backpropagation learning algorithm [40]. The inputs of the network were each image pixel's value, and the output was the correspondent segmentation region. Further details of the neuronal network used can be found in [41]. After the identification of the three regions presented in the input image, the diameter and area values were computed: the diameters by searching for the longest diagonal within the delaminated region, and the areas by summing up the pixels within the associated regions.

The values obtained from the radiography images were used to determine the delamination factor, $F_{d},[19]$, the adjusted delamination factor, $F d a,[18]$ and the circularity factor, according to Eqs. $(2,4)$ and (5) (see Section 2.2).

So, taking advantage of the computational techniques of imaging processing and analysis, the adjusted delamination factor was the criterion used in this work for damage assessment.

\subsection{Mechanical testing}

The mechanical test carried out was the "Bearing test" according to ASTM D5961M-10 [23]. This test was used to assess the effect of the delamination extension on the mechanical properties of the drilled plates in the joint area. Procedure A - double-shear was used, as represented in Fig. 8 [42]. This procedure uses a single fastener and is recommended for material evaluation and comparison.

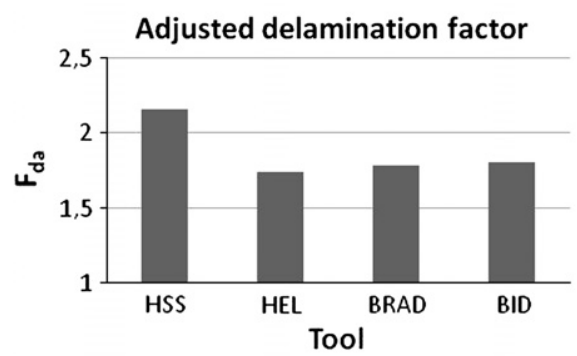

(b)



(d)

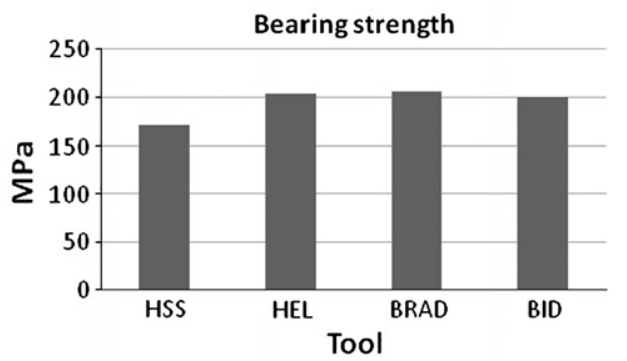

(f) 
Fig. 9. Influence of feed rate and tool material/geometry, respectively on: (a and b) adjusted delamination factor; (c and d) circularity; (e and $\mathrm{f}$ ) bearing strength. 
Table 1

Results of delamination criteria, circularity and bearing test for the three feed rates studied.

\begin{tabular}{|c|c|c|c|c|}
\hline $\begin{array}{l}\text { Feed } \\
\text { rate } \\
(\mathrm{mm} / \mathrm{rev}\end{array}$ & $\begin{array}{l}\text { Delaminat } \\
\text { ion } \\
\text { factor, }\end{array}$ & $\begin{array}{l}\text { Adjust } \\
\text { delamination } \\
\text { Fd }\end{array}$ & $\begin{array}{l}\text { Circularity, } \\
\text { Bearing }\end{array}$ & $\begin{array}{l}f \\
\text { factor, }\end{array}$ \\
\hline$\underline{F} d c_{03}$ & 1.29 & test, $\mathrm{MPa}$ & 0.14 & 203 \\
\hline 0.10 & 1.61 & 1.81 & 0.10 & 195 \\
\hline 0.20 & 2.04 & 2.33 & 0.08 & 178 \\
\hline
\end{tabular}

Table 2

Results of delamination criteria, circularity and bearing test for tool geometries and tool materials.

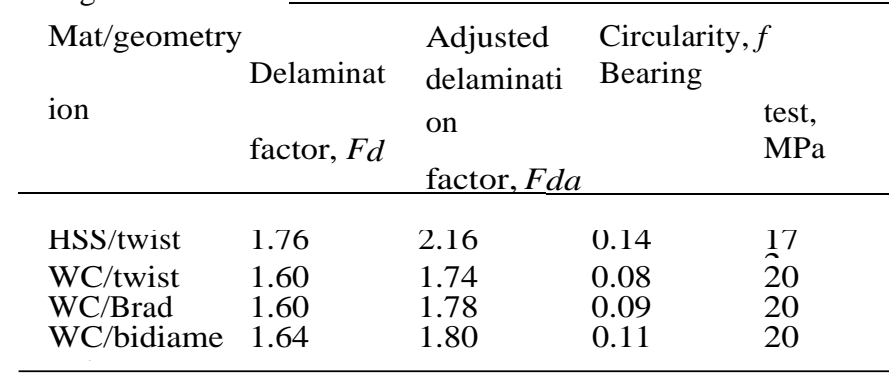

The tests were performed in a Shimadzu AG-X/100 kN Universal Testing machine equipped with the necessary accessories to run the different tests and connected to a computer for machine control and data acquisition. The head displacement speed was set to $2 \mathrm{~mm} / \mathrm{min}$.

The purpose of this mechanical test was to establish a comparison between the results obtained for plates drilled under different conditions regarding tool geometry or feed rate.

\section{Results and discussion}

The results of maximum thrust force variation according to drill geometry and feed rate were largely published and discussed, see for example [10,12,13,17,21,22,24,27,43]; so, in this work, no data is added to the existing information. According to that extensive published work, it is possible to say that higher feeds result in higher thrust forces. It is also possible to say that different geometries cause a variation in the thrust force evolution during drilling and, consequently, on the values of the maximum force obtained during drilling, all the other factors remaining constant: plate characteristics and drill diameter. It is also known that higher diameters cause larger thrust forces. However, the main focus in this work was on the damage assessment and mechanical consequences in terms of bearing resistance, so this issue is not discussed hereby.

\subsection{Delamination assessment}

Delamination assessment was carried out according to the procedure described in Section 3.2. The average results concerning all the combinations of feed rates and drills are presented in Tables 1 and 2 and in Fig. 9a and b. From these results, it is possible to conclude that, as expected, the increase in the feed rate had a direct effect in the delamination extension, for both assessment criteria. Based on these results and on the previous works referred above, a shape (IC = 1). This can be the consequence of the higher energy transferred from the tool to the composite coupon when feed rate is higher. As the drill chisel edge acts more like a punch, higher feed rate corresponds to a higher linear extrusion speed, thus more

energy is transmitted to the uncut plies. So, this result confirms the known recommendation of using feed rates as low as possible when drilling composite plates.

The results from the damage extension and circularity related with tool geometry are presented in Table 2 and in Fig. 9d. As the effect of the feed rate was discussed in the precedent paragraph, only the effect of the tool is discussed here. So, the table presents average values for the three feed rates used in the experimental work in order to reduce the amount of data

presented.

Analysing the results presented in Table 2 and in Fig. 9, the tool

clear connection between the thrust force results and the delamination extension can be established. The drilling conditions with less damage corresponded to the coupons associated to the lowest feed rate, as a consequence of lower thrust forces during drilling.

An interesting result is the evolution of the circularity of the damaged area with feed rate, as this value decreased while the feed rate increased, see Table 1 and Fig. 9c. This outcome suggests that for higher feed rates the damaged area, besides its greater exten- sion, has an extended shape, far from the circumferential reference 
influence is clear, although not very different from any geometry to any other. Damage in unidirectional drilled plates differs according to the tool geometry and material, under the experimental conditions described. Considering the tool geometry influence, the low-est values of damage extension were those obtained for the plates drilled with carbide twist drill. Damage from Brad drills was $2 \%$ higher when considering the adjusted delamination factor and for bidiametral drills was approximately 3\% higher. Finally, confirming the fact that HSS drills should not be used for drilling carbon/epoxy composites, damage extension was always the high-est, approximately $24 \%$ on the average.

From these results, it is possible to state that, more than the tool influence is the selection of an appropriate combination of tool geometry considering the stacking sequence of the plate that must be always in mind when defining the drilling conditions. Naturally, the feed rate has to be kept as low as possible, in order to minimize damage extension. The limit on this condition is to be given by the need to avoid unwanted thermal damages that result from the matrix softening and the need, in industrial terms, to ensure a reasonable number of hourly productions.

Finally, analysing the results of circularity of the damaged region, the holes machined with HSS drills were those with higher result of this value, so closer to a perfect round shape, suggesting that the tool geometry and material have a strong influence on this effect. This outcome can be a consequence of the larger area of thedelaminated region for plates drilled with HSS drills, causing an in- crease in the IC factor, see Eq. (5). As for all the plates the perimeter is higher, due to its irregular contour, the final result of IC is small and a difference in the area can turn out in results as those pre- sented in Table 2. For the carbide tools' geometry the circularity values were always lower and it seems that there is some influence of the tool geometry, as plates with less delamination extensionalso have lower values of IC, opposite to the observed effects forthe feed rate.

\subsection{Mechanical testing}

The results of the bearing test for the different combinations of feed rate and tool geometry are presented in Tables 1 and 2 and in Fig. 9e and f. Observing these results it is evident that there is some influence of the feed rate on the bearing resistance of the plates, as plate strength lowers with increasing feed rate. According to expectations, higher feed rates had caused a greater loss of mechanical properties of the plate. The difference from the values obtained with plates drilled with $0.03 \mathrm{~mm} / \mathrm{rev}$ feed rate from those drilled with a feed rate of $0.20 \mathrm{~mm} / \mathrm{rev}$ was about $13 \%$. This result means that higher feed rates are to be avoided when drilling composite plates.

Table 2 and Fig. 9f present the average results for bearing test considering drill geometry or material. In this case, the importance of drill geometry is easily evidenced. The highest results of bearing 
strength were obtained with tungsten carbide Brad drill machined plates, although the final result is almost equal to those for plates drilled with tungsten carbide twist drill. For the bidiametral geometry, the final result is lower but only for 3\%. The greater difference is related with tool material. Considering the twist drill geometry, there is a drop of strength of $16 \%$ just by changing from tungsten carbide to high speed steel. So, it is possible to conclude that tool material plays a more important role in this property than the drill geometry. This outcome has to be seen as a key factor in damage onset and propagation. Hence, a good selection of the tool, combined with a proper feed rate can reduce damage extension.

Correlations for damage extension to bearing resistance, using either one of the methods of Eqs. (2) and (3), did not return any valid result. More data will be needed in order to confirm this assumption.

The influence of the circularity on the mechanisms of damage propagation during bearing test could not be established. The importance of circularity on the mechanical resistance of the plate, as an outcome of the bearing test result, has to be further investigated.

\section{Conclusions}

In this work, unidirectional carbon fibre/epoxy laminates plates were drilled with the objective of comparing the performance of three different tool geometries, combined with three feed rates. One of the drills - twist drill - had two distinct materials. Relevant results considered for assessment were the delamination extension by the Delamination factor and by the Adjusted delamination factor, circularity of the damaged area by the Circularity Index and the mechanical strength by the Bearing stress test. According to the re- sults of the experimental work presented in the precedent sections, the following conclusions were possible.

The feed rate influence on damage onset and propagation is well known and the results confirmed that higher feed rates corre- spond to higher delamination extension, whatever the criterion that was used. So, feed rates should be kept as conservative as pos- sible, in order to avoid large delamination around the drilled hole. When considering the machining of composite plates, particularly drilling, a good combination of tool geometry com- bined with an adequate feed rate for the stacking sequence of the plate is essential in order to have worthy results for minimum

delamination.

Circularity of the damaged region was higher - closer to circular shape - for holes obtained with HSS drills. For carbide drills, no influence of tool geometry on this shape parameter was recognized. No correlation between circularity and damage extension or bearing strength was found.

The mechanical tests showed the influence of both drill geometry and feed rate. Higher strength was found for plates drilled with carbide twist drill and lower feed rate.

The present experimental work shows the importance of a careful planning of drilling operations in composite plates, by selecting appropriate machining conditions keeping in mind the plate stacking sequence, in order to reduce delamination damage.

\section{Acknowledgements}

This work was supported by FCT (Fundação para a Ciência e a Tecnologia) - Portugal, in the scope of the strategic funding Project PEst-OE/EME/UI0615/2011.

The third author thanks to National Council for Research and Development $(\mathrm{CNPq})$ and Cearense Foundation for the Support of
Scientific and Technological Development (FUNCAP) for providing financial support through a DCR Grant (Project Number 35.0053/ 2011.1) to UNIFOR. 
The authors would like to express their recognition to the mechanical workshop of ISEP, particularly to Eng. Victor Ribeiro and Eng. Ricardo Chita for their contribution to the completion of this work.

\section{References}

[1] Gilpin A. Tools solutions for machining composites. Reinf Plast 2009:30-4. [2] Chandrasekharan V, Kapoor SG, DeVor RE. A mechanistic approach to predicting the cutting forces in drilling: with application to fibre-reinforced composite materials. J Eng Ind 1995;117:559-70.

[3] Boldt JA, Chanani JP. Solid-tool machining and drilling. Engineered Materials Handbook, ASM International Handbook Committee, vol. 1; 1987. p. 667-672.

[4] Wern CW, Ramulu M, Schukla A. Investigation of stresses in the orthogonal cutting of fiber-reinforced plastics. Exp Mech 1994:33-41.

[5] Persson E, Eriksson I, Zackrisson L. Effects of hole machining defects on strength and fatigue life of composite laminates. Composites A 1997;28:141-51.

[6] Abrate S. In: Mallick PK, editor. Machining of composite materials. Composites engineering handbook. New York: Marcel Dekker; 1997. p. 777-809.

[7] Piquet R, Ferret B, Lachaud F, Swider P. Experimental analysis of drilling damage in thin carbon/epoxy plate using special drills. Composites A 2000;31:1107-15.

[8] Park KY, Choi JH, Lee DG. Delamination-free and high efficiency drilling of carbon fibre reinforced plastics. J Compos Mater 1995;29:1988-2002.

[9] Stone R, Krishnamurthy K. A neural network thrust force controller to minimize delamination during drilling of graphite-epoxy composites. Int $\mathrm{J}$ Mach Tools Manuf 1996;36:985-1003.

[10] Davim JP, Reis P. Drilling carbon fibre reinforced plastics manufactured by autoclave - experimental and statistical study. Mater Des 2003;24:315-24.

[11] Tsao CC, Hocheng H. Effects of exit back-up on delamination in drilling composite materials using a saw drill and a core drill. Int $\mathbf{J}$ Mach Tool Manuf 2005;45:1261-70.

[12] Hocheng $\mathrm{H}$, Tsao CC. Effects of special drill bits on drilling-induced delamination of composite materials. Int J Mach Tool Manuf 2006;46:1403-16.

[13] Tsao CC, Hocheng H. Parametric study on thrust force of core drill. J Mater Process Technol 2007;192193:37-40.

[14] Fernandes M, Cook C. Drilling of carbon composites using a one shot drill bit. Part II: empirical modelling of maximum thrust force. Int $\mathrm{J}$ Mach Tool Manuf 2006;46:76-9.

[15] Tsao CC. The effect of pilot hole on delamination when core drilling composite materials. Int J Mach Tool Manuf 2006;46:1653-61.

[16] Tsao CC. Effect of pilot hole on thrust force by saw drill. Int J Mach Tool Manuf 2007;47:2172-6.

[17] Dharan CHK, Won MS. Machining parameters for an intelligent machining system for composite laminates. Int J Mach Tool Manuf 2000;39:415-26.

[18] Davim JP, Campos Rubio JC, Abrão AM. A novel approach based on digital image analysis to evaluate the delamination factor after drilling composite laminates. Compos Sci Technol 2007;67(9):1939-45.

[19] Chen WC. Some experimental investigations in the drilling of carbon fibre- reinforced plastic (CFRP) composite laminates. Int J Mach Tool Manuf 1997;37:1097-108.

[20] Faraz A, Biermann D, Weinert K. Cutting edge rounding: an innovative tool wear criterion in drilling CFRP composite laminates. Int $\mathrm{J}$ Mach Tool Manuf 2009;49:1185-96.

[21] Durão Luís MP, Gonçalves Daniel JS, Tavares João MRS, de Albuquerque Victor HC, Vieira AA, Marques AT. Drilling tool geometry evaluation for reinforced composite laminates. Compos Struct 2010;92:1545-50.

[22] Durão Luís MP, Tavares João MRS, Marques AT, Baptista AM, Magalhães AG. Damage analysis of carbon/epoxy plates after drilling. Int J Mater Prod Technol 2008;32(2/3):226-42.

[23] ASTM D5961/D5961M-10. Standard test method for bearing response of polymer matrix composite laminates. ASTM International; 2010.

[24] Hocheng H, Dharan CKH. Delamination during drilling in composite laminates. J Eng Ind 1990;112:236-9.

[25] Hocheng H, Tsao CC. The path towards delamination-free drilling of composite materials. J Mater Process Technol 2005;167:251-64.

[26] Palanikumar K, Campos Rubio J, Abrão A, Esteves A, Davim JP. Statistical analysis of delamination in drilling glass fiber-reinforced plastics (GFRP). J Reinf Plast Compos 2008;27:1615-23.

[27] Campos Rubio J, Abrão AM, Faria PE, Esteves Correia A, Davim JP. Effects of high speed in the drilling of glass fibre reinforced plastic: evaluation of the delamination factor. Int J Mach Tool Manuf 2008;48:715-20.

[28] Campos Rubio JC, Abrão AM, Faria PE, Correia AE, Davim JP. Delamination in high speed drilling of carbon fiber reinforced plastic (CFRP). J Compos Mater 2008;42:152332.

[29] Hosur MV, Chowdhury F, Jeelani S. Low-velocity impact response and ultrasonic NDE of woven carbon/epoxynanoclay nanocomposites. J Compos Mater 2007;41:2195212.

[30] Jong HJ. Transverse cracking in a cross-ply composite laminate - detection in acoustic emission and source characterization. J Compos Mater 2006;40:37-69.

[31] de Albuquerque VHC, Tavares JMRS, Durão Luís MP. Evaluation of delamination damages on composite plates from radiographic image processing using an artificial neural network. J Compos Mater 2010;44:1139-59. 
[32] Johnson WS, Treasurer P, Woodruff GW. Radiographic investigation of the effects of ply modification on damage development in laminates containing circular holes. J Compos Mater 2008;42:2143-61.

[33] Tsao CC, Hocheng H. Computerized tomography and CScan for measuring delamination in the drilling of composite materials using various drills. Int $\mathrm{J}$ Mach Tool Manuf 2005;45:1282-7.

[34] Wang LB, Frost JD, Voyiadjis GZ, Harman TP. Quantification of damage parameters using X-ray tomography images. Mech Mater 2003;35:777-90.

[35] Schilling PJ, Karedla BPR, Tatiparthi AK, Verges MA, Herrington PD. X-ray computed microtomography of internal damage in fiber reinforced polymer matrix composites. Compos Sci Technol 2005;65:2071-8.

[36] Mehta M, Reinhart TJ, Soni AH. Effect of fastener hole drilling anomalies on structural integrity of PMR-15/Gr composite laminates, In: Proc. of the Machining Composite Materials Symposium. ASM Materials Week; 1992. p. 113-26.

[37] Durão Luís MP, Magalhães AG, Tavares JMRS, Marques AT. Analyzing objects in images for estimating the delamination influence on load carrying capacity of composite laminates. Electron Lett Comput Vis Image Anal 2008;7(2):11-21.
[38] Bodyanskiy Y, Kolodyazhniy V, Otto P, Neuro-fuzzy Kolmogorov's network for time series prediction and pattern classification, LNCS 3698, Springer; 2005 p. 91202.

[39] Elliott DL. Better A. Activation function for artificial neuronal network. ISR technical report TR 93-8. Institute for Systems Research, University of Maryland; 1993.

[40] Singh V, Rao SM. Application of image processing and radial basis neuronal network techniques for ore sorting and ore classification. Miner Eng 2005;18:1412-20.

[41] de Albuquerque VHC, Silva CC, Menezes TIS, Farias JP, Tavares JMRS. Automatic evaluation of nickel alloy secondary phases from SEM images. Microsc Res Tech 2011;74(1):36-46.

[42] Thoppul SD, Finegan J, Gibson RF. Mechanics of mechanically fastened joints in polymer-matrix composite structures - a review. Compos Sci Technol 2009;69:301-29.

[43] Durão Luís MP, Marques António T, Magalhães AG, Silva JF, Tavares João Manuel RS. Delamination analysis of carbon fibre reinforced laminates: evaluation of a special step drill. Compos Sci Technol 2009;69:2376-82. 